\title{
Risk analysis and reliability based design in tunnel fire safety
}

\author{
M. Guarascio, M. Lombardi, G. Rossi \& G. Sciarra \\ Safety Engineering "Sapienza" - Rome University, Italy
}

\begin{abstract}
In this paper the quantitative risk analysis procedure has been used to face two specific aspects of the fire safety design in road and rail tunnel:

- the smoke control system effectiveness;

- the spalling effect and structural reliability of the liners.

The first example deals with the risk comparative assessment of two alternative systems for smoke control in a road tunnel. The societal risk indicator has been used to select the more effective system.

The second one aims to consider a reliability based approach for structural design of the tunnel liners in order to identify the design fire load preventing from the spalling effect at a given probability level.

Keywords: quantitative risk indicators, residual risk flow, back cumulated risk distribution, structural reliability, design point, safety margin, thermo-fluiddynamic analysis.
\end{abstract}

\section{Introduction}

The requirement to be implemented to ensure the compliance with given safety targets both in road and rail tunnels is discussed in the two issues here below:

(i) risk identification and mitigation during transit in the tunnels through the analysis of the effectiveness of prevention and protection measures;

(ii) definition of appropriate quantitative risk indicators.

Quantitative risk analysis develops, for a given tunnel system and for any traffic condition, the probabilistic damage consequences distribution associated to a specific accident occurrence.

As far as the damage evaluation the risk analysis allows to introduce indicators like $\mathrm{N}$ (normalized number of fatalities) and D (equivalent economic 
damage), both relevant in safety management, insurance and optimal investment allocation purposes.

Then the risk assessment can be based upon the bi-variated distribution of the two random variables $\mathrm{N}$ and $\mathrm{D}$ (see fig. 1).

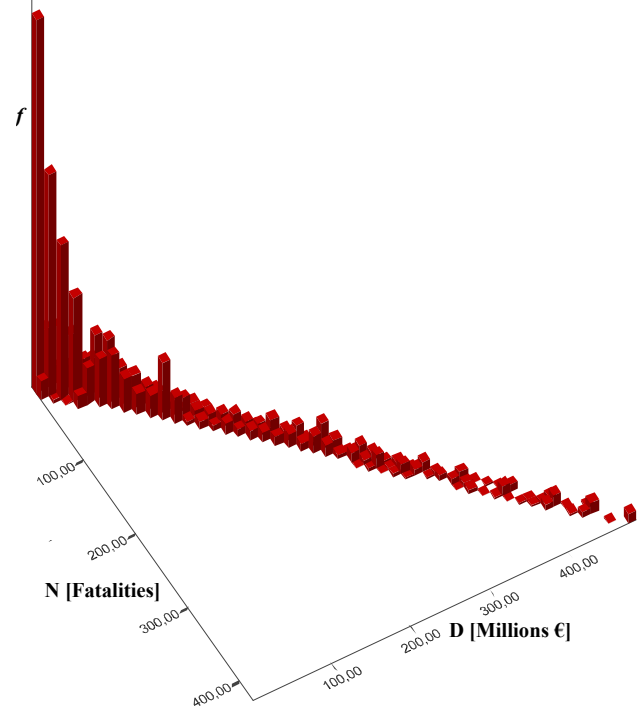

Figure 1: Bi-variated $\mathrm{N}$ and $\mathrm{D}$ probability distribution.

\section{Methodology: hazard, protection and consequences event tree analysis}

The risk evaluation procedure starts with the identification of the hazardous circumstances occurring when root events evolve and generate an initiating critical event.

A complete representative set of critical events, which are mutually exclusive, is established and their probabilities are conveniently evaluated.

From any among the above initiating events, several consequences scenarios are likely to develop.

The probabilities of the all consequences scenarios are appropriately evaluated through the Event Tree Analysis procedure.

Figures 2 and 3 show the graph, usually named Bow-Tie Model, where the sequential structure of events from the causes to the consequences is represented according a Boolean logic, which guarantees the mutually exclusive condition of the final consequences events. Each events path includes a given initiating event (IE) combined with events accounting for the effectiveness and reliability of the protection/mitigation systems coupled with the exposure conditions of the persons involved in the hazard scenarios. 
The numerical values obtained for the final damage indicators $\mathrm{N}$ and/or $\mathrm{D}$, together with their probabilities, allow to calculate the Back-Cumulated probability distributions and compare with criteria of Risk Acceptability like the ALARP or the ANAS Standard which have been established in Italy for the tunnels of the national road network.

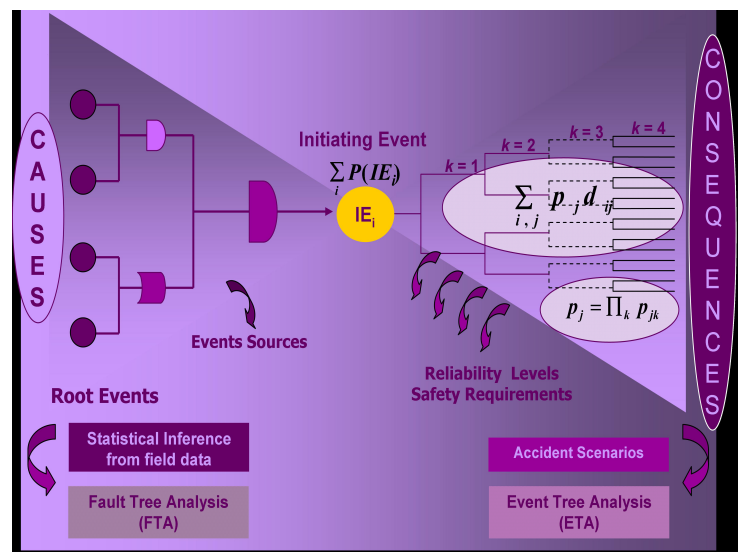

Figure 2: $\quad$ Bow tie model: $\mathrm{P}\left(\mathrm{IE}_{\mathrm{i}}\right)=$ probability of the $\mathrm{i}^{\text {th }} \mathrm{IE}_{\mathrm{i}}, \mathrm{p}_{\mathrm{j}}=$ probability of the $\mathrm{j}^{\text {th }}$ hazard scenario, $\mathrm{p}_{\mathrm{jk}}=$ reliability of the $\mathrm{k}^{\text {th }}$ safety requirement.

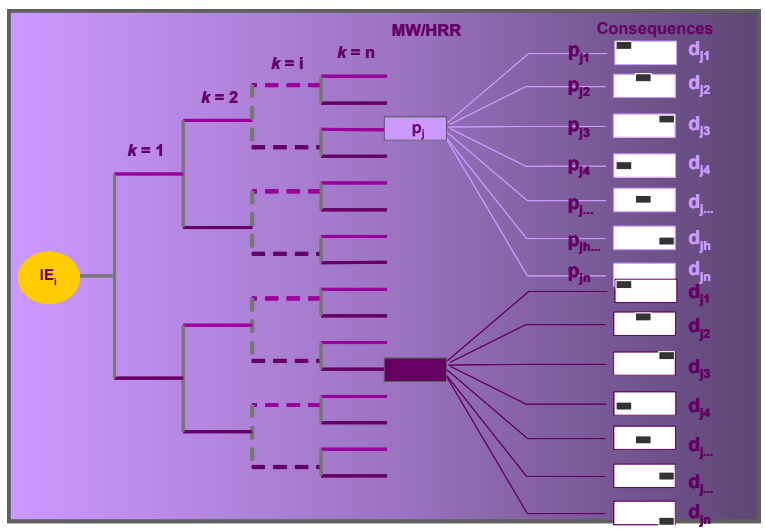

Figure 3: Event tree analysis: $\mathrm{p}_{\mathrm{jh}}=$ probability of the $\mathrm{h}^{\text {th }}$ consequences event given the $\mathrm{j}^{\text {th }}$ hazard scenario, $\mathrm{d}_{\mathrm{jh}}=$ severity of the $\mathrm{h}^{\text {th }}$ consequences event given the $\mathrm{j}^{\text {th }}$ hazard scenario.

In the above case the Quantitative Risk Analysis must be used for any tunnel to verify the compliance with specific acceptability criteria as illustrated in figure 4. 


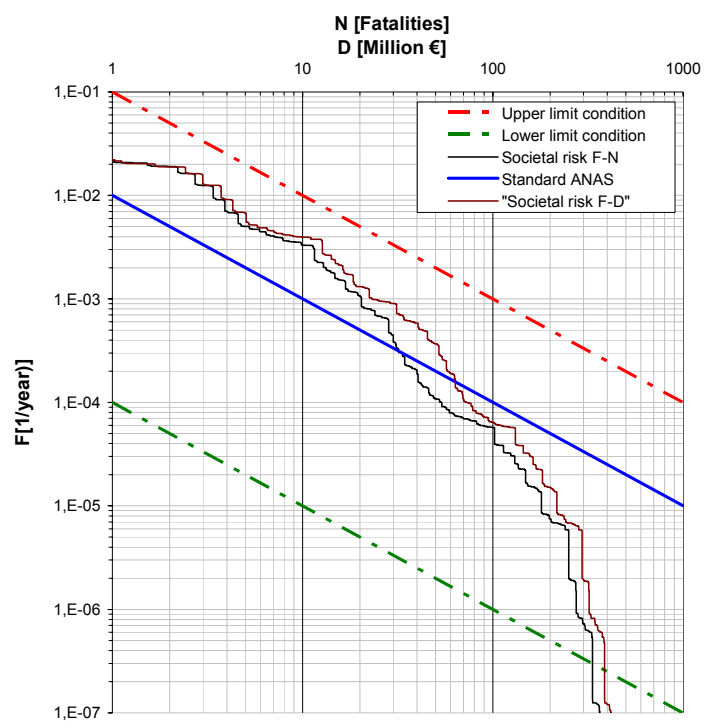

Figure 4: Societal risk picture: back cumulated risk distribution (BCR) so called FN curve (probability $\mathrm{P}(\mathrm{N} \geq \mathrm{Nt})$ /year-tunnel).

\section{Comparative performance-based effectiveness analysis between two air and smoke control systems}

Let us consider a two-lane tunnel of $2000 \mathrm{~m}$ length with bi-directional traffic conditions. The cross-section area is $54 \mathrm{~m}^{2}$ and the traffic volume is given together with the people exposure in case of accident.

Safety requirements for fire detection/alarm and access control as for as the emergency lightening system are specified according to the law.

As far as the air and smoke control protection systems two alternative design solutions have been compared according their level of compliance with the risk acceptability criteria of the Italia law (ALARP) and of the ANAS, the Italian public road network ANAS guidelines (Standard ANAS).

The first protection solution consists of a longitudinal ventilation system with a given capacity of air control and smoke evacuation.

The second protection solution is based upon the construction of two chimneys in the overburden providing aspiration capacity and supporting a smoke extraction system in the roof of the tunnel.

The differential effectiveness of the two different protection capacities corresponding to alternative design solutions has been measured and emphasized with the help of "Fire Dynamic Simulator", a well known computational fluiddynamic numerical tool coupled with proprietary codes reproducing the exposure and people evacuation conditions. 
The probabilities are evaluated through the Event Tree Analysis. The results shown in figure 4 account for a significant effectiveness improvement when the smoke extraction system is adopted, normally in the case of the hazardous events correlated with consequences severity indicator less then $\mathrm{N}=30$.

Furthermore the second smoke protection system is fully compliant with the Standard ANAS risk acceptability criterion.

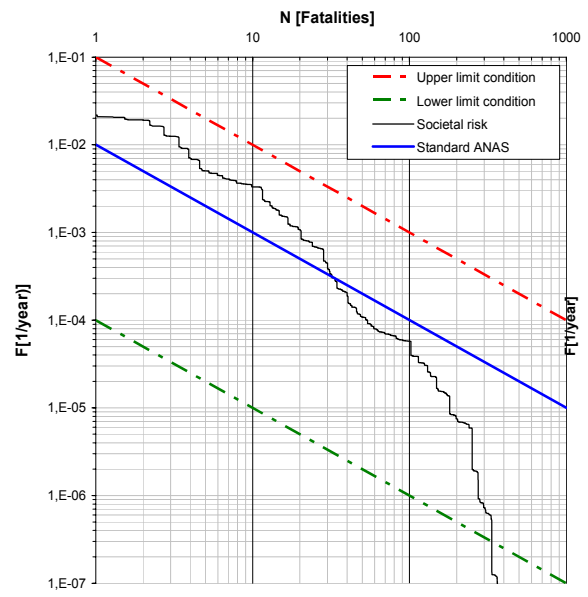

a)

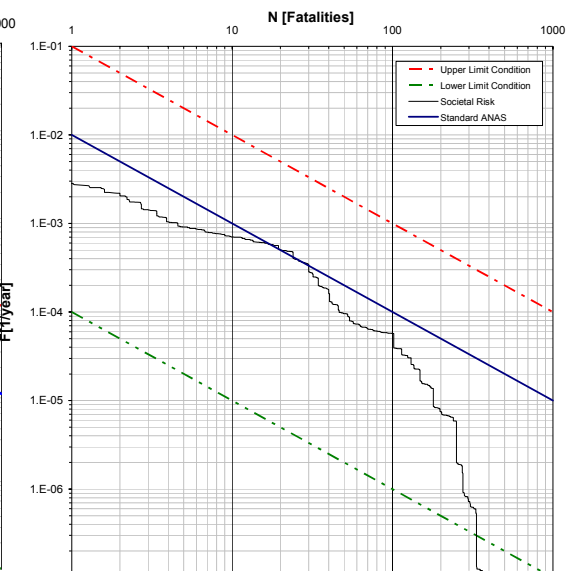

b)

Figure 5: a) BCR longitudinal ventilation system; b) BCR air and smoke control system.

\section{Reliability design of the tunnel liners}

Let consider a fire event occurring in a tunnel of a given cross-section and a specified concrete liner.

To characterize the fire propagation in the roof and eventually identify the spalling effect conditions the following assumptions will be considered:

(i) The curve describing the Heat Release Rate (HRR) as a function of time is assumed to be the product of two Heavyside functions $\operatorname{HRR}(t)=H(t)\left(1-H\left(t-t_{\text {fin }}\right)\right)$. The rising step is concentrated in $t=0$ the descending one in $t=t_{f i n}$ The growing and the decay phases collapse therefore in two points, while the steady condition coincides with the whole history of fire evolution. As a consequence the fire load, per unit area, is simply the product of the maximum value of HRR, say $Q$, times the characteristic time interval: $q=Q t_{\text {fin }}$;

(ii) The gas temperature just beneath the ceiling, in a suitable neighbourhood of the fire source, is constant in time during fire development and is determined considering semi-empirical formulas for the net heat flux, see e.g. [9]. 
(iii) The temperature distribution through the thickness of the liner is assumed to be described by classical Fourier's conduction model (see Fig. 6), where initial and boundary conditions are given by: $T(z, 0)=T_{\text {env }}, T(0, t)=T_{\text {fire }}, T^{\prime}(1, t)=0 . T_{\text {env }}$ and $T_{\text {fire }}$ are the ambient temperature and the temperature of the ceiling due to fire, respectively.

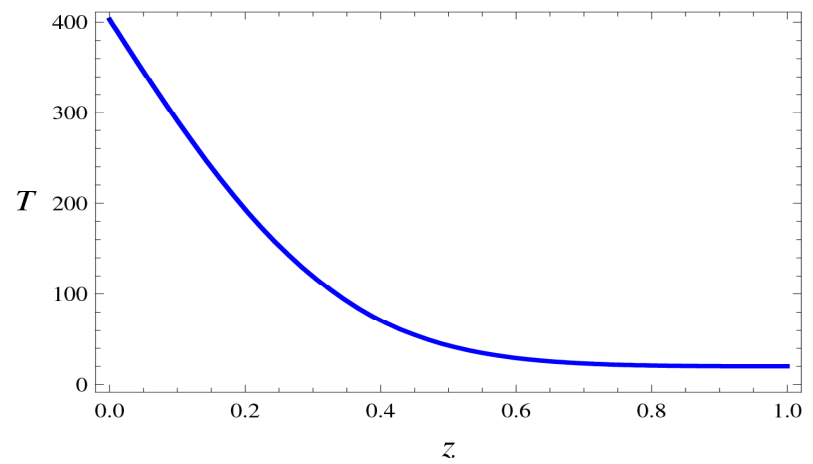

Figure 6: Temperature through the thickness of the liner; $\mathrm{z}=0$ corresponds to the ceiling of the tunnel.

The previous assumptions allow for a quantitative characterization of the critical conditions with respect to thermal spalling, in terms of the following Safety Margin function $M S$ :

$$
\operatorname{MS}\left(Q, T_{c r} ; z, t\right)=T_{c r}-T(Q ; z, t) .
$$

$T_{c r}$ is the critical value of temperature triggering the spalling phenomenon; $T(Q ; z, t)$ assigns the temperature as a function of the maximal HRR, $Q$, when varying space, i.e. distance from the heated surface, and time. As already noticed the thickness of the layer of the concrete tunnel liner, interested by thermal spalling, is typically smaller than $5 \mathrm{~cm}$, when considering short time behaviour.

Reliability design consists, in this framework, in the identification of the design value of the maximal HHR, $Q$, and the corresponding safety factor, with respect to a suitable characteristic value, when a target probability of failure, conditioned by fire accident, has been fixed.

The target probability, and consequently the target safety index $\beta_{T}$, are determined considering

$$
P(\text { Failure } \mid \text { Fire })=P(\text { Failure }) / P(\text { Fire })
$$

where $P($ Failure $)=0.0000723$ is the target probability of ultimate limit states, according with EN 1990 [6], while $P($ Fire $)=0.008$ corresponds to the probability of fire in wide areas.

First Order Reliability Methods (FORMs) can be adopted to provide an estimate of the expected value $\mu_{Q}$ of the maximal HRR and consequently of the design values $Q^{d}$ and $T^{d}$ of $Q$ and $T_{c r}$. 
The design point $P^{d}$ in the plane $\pi$ of standardized normal uncorrelated variables is

$$
P^{d}=\left(\left(\left(Q^{d}-\mu_{Q}\right) / \sigma_{Q}\right), Y\right)
$$

where $Y:=\left(\ln \left(T_{c r}\right)-\lambda_{T r}\right) / \sigma_{T_{c r}}$ is the equivalent standardized normal variable associated with the critical temperature; $P^{d}$ is the most central point on the curve $M S\left(Q, T_{c r} ; \bar{z}, \bar{t}\right)=0$, see [2], when fixing a reference distance $\bar{z}$ from the heated surface towards the inner liner and a characteristic time $\bar{t}$.

The aforementioned time parameterization, associated with the considered reliability index and a reference distance $\bar{z}=5 \mathrm{~cm}$, provides the plots of the design maximal HRR given in figure 7.

In fig. 8 the picture of the limit curve and the coordinates of the design point are plotted in the space of standardized normal variables.

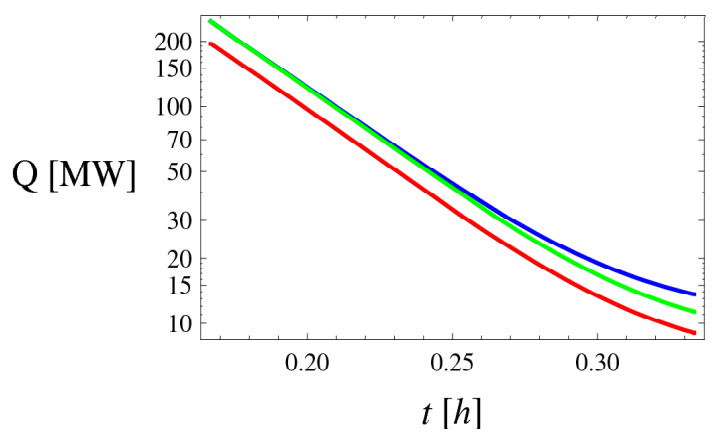

Figure 7: Maximal HHR plotted against time. The blue line corresponds to the design value of $\mathrm{Q}$, the red line to its expected value and the green one to the characteristic value associated with the $80 \%$ fractile of the normal distribution.

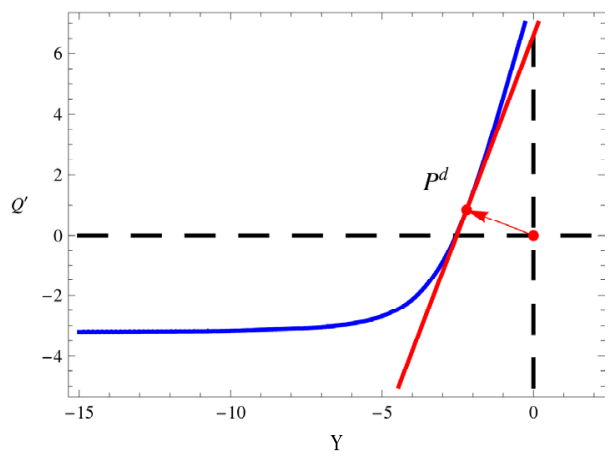

Figure 8: $\quad\left(Y, Q^{\prime}\right)$ are the standardized normal variables affecting the behaviour of the safety margin. The blue line is the limit curve characterized by the equation $M S(Y, Q)=0$ the red line is the linearization of the limit curve in the neighbourhood of the design point $P^{d}$. 
The fire event associated with a maximal HRR of $10 \mathrm{MW}$ and the flash point at 10 min represents a quite frequent occurrence both in road and rail tunnels.

Thermofluidodynamic analysis is developed in order to simulate the temperature the $\mathrm{CO}$ and the optical density fields in the tunnel, by means of the Fire Dynamic Simulator (FDS) code (NIST National Institute of Standards and Technology).

Figure 9 shows simulation results of temperature field for two representative times:

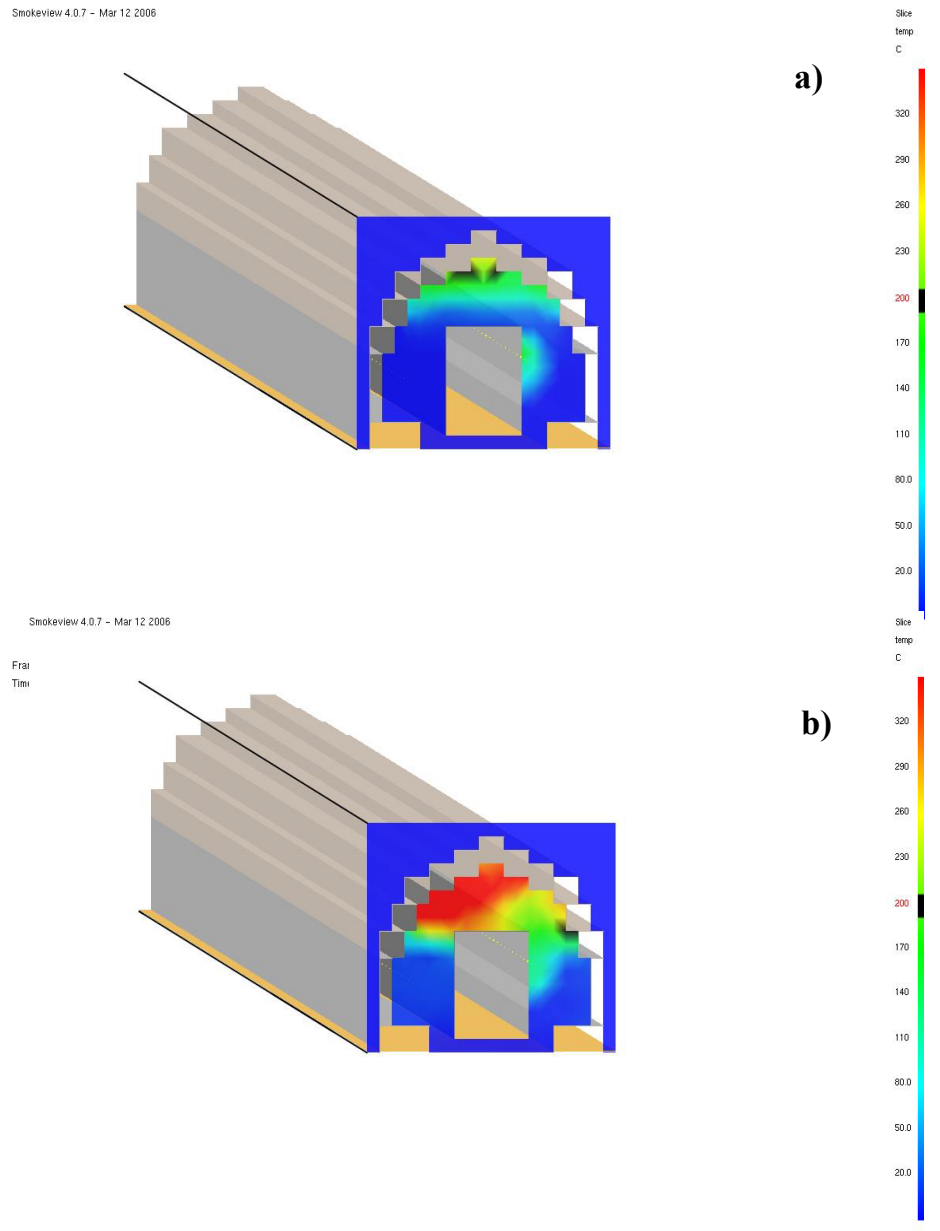

Figure 9: $\quad$ Temperature field simulation results - a) $\mathrm{t}=200 \mathrm{~s}, \mathrm{~T}=220^{\circ} \mathrm{C}$; b) $\mathrm{t}=840 \mathrm{~s}, \mathrm{~T}=350^{\circ} \mathrm{C}$. 
In the table and graph below the time distribution of ceiling temperature values is presented at given distances from the fire. Both directions along the tunnel are considered taking into account also the piston effect which induces an asymmetrical temperature distribution around the fire.

Table 1: $\quad$ Time distribution of ceiling temperature values.

\begin{tabular}{|l|l|l|l|l|l|l|l|}
\hline \multicolumn{1}{|c|}{ Time (s) } & 0 & 180 & 360 & 540 & 720 & 1800 & 3600 \\
\hline $\begin{array}{c}\text { distance of fire } \\
(\mathrm{m})\end{array}$ & \multicolumn{7}{|c|}{ Ceiling Temperature $\left({ }^{\circ} \mathrm{C}\right)$} \\
\hline-50 & 20 & 20 & 100 & 160 & 170 & 230 & 250 \\
\hline-40 & 20 & 20 & 100 & 190 & 210 & 250 & 280 \\
\hline-30 & 20 & 20 & 100 & 250 & 300 & 320 & 320 \\
\hline-20 & 20 & 20 & 200 & 350 & 370 & 370 & 370 \\
\hline-10 & 20 & 20 & 290 & 360 & 370 & 370 & 370 \\
\hline 0 & 20 & 20 & 300 & 300 & 320 & 320 & 320 \\
\hline+10 & 20 & 110 & 350 & 370 & 400 & 400 & 400 \\
\hline+20 & 20 & 80 & 230 & 340 & 370 & 400 & 400 \\
\hline+30 & 20 & 70 & 200 & 250 & 270 & 350 & 350 \\
\hline+40 & 20 & 60 & 150 & 200 & 230 & 280 & 290 \\
\hline+50 & 20 & 50 & 110 & 160 & 180 & 230 & 250 \\
\hline
\end{tabular}

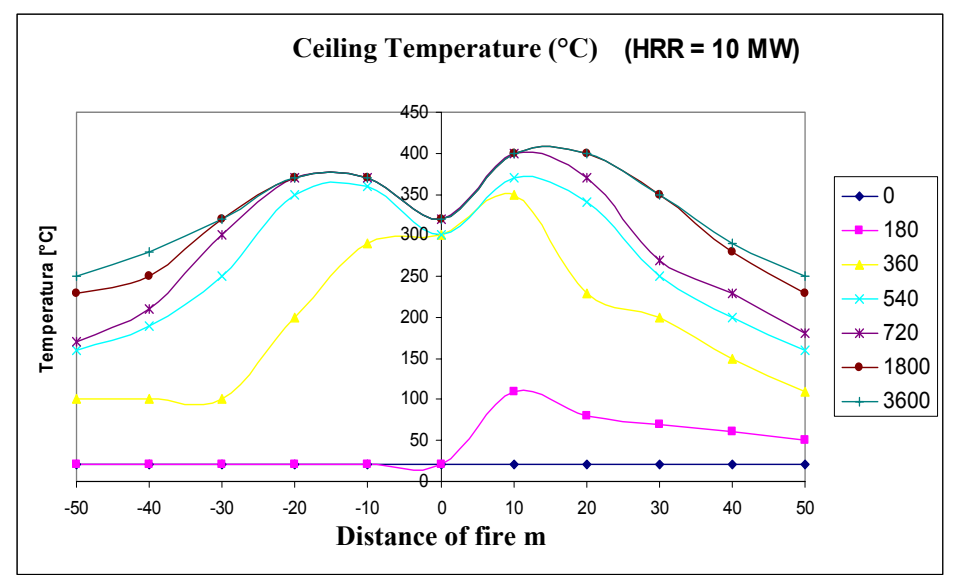

Figure 10: Asymmetrical temperature distribution around the fire (piston effect). 


\section{Conclusive remarks}

Risk and reliability analysis are effective and necessary tools in most of the problems of the Fire Safety Engineering.

The performance based design approach addresses the choice among different protection system solutions aiming to comply with given safety targets and risk acceptability criteria.

The results of the case studies shown in this paper offer very good examples of the above statements in the case of tunnels design, when considering fire scenarios.

\section{References}

[1] Cadorin J-F., Pintea D., Dotreppe J-C., Franssen J-M., A tool to design steel elements submitted to compartment fires-OZone V2. Part 2: Methodology and application Fire Safety Journal 38 (2003) 429-451.

[2] Ditlevsen O., Madsen H.O., Structural Reliability Methods, Wiley, 1996.

[3] Gawin D., Pesavento F., Schrefler B. A., Modelling of deformations of high strength concrete at

elevated temperatures. Materials and Structures/Concrete Science and Engineering 37 (2004) 218-236.

[4] Gawin D., Pesavento F., Schrefler B.A., Towards prediction of the thermal spalling risk through

a multi-phase porous media model of concrete Comput. Methods Appl. Mech. Engrg. 195 (2006) 5707-5729.

[5] Guarascio M., Lombardi M., Rossi G., Sciarra G., Risk analysis and acceptability criteria. Safety and Security Engineering II, WITPress 2007.

[6] Guarascio M., Lombardi M., Rossi G., Sciarra G.., Road tunnel safety rules in Italy: the tunnel country. Safety and Security Engineering II, WITPress 2007.

[7] Kohl B., Walet F., Risk Analysis for road tunnel, PIARC Reference 2008R02, 2008.

[8] Witek A., Gawin D., Pesavento F., Schrefler B.A., Finite element analysis of various methods for protection of concrete structures against spalling during fire Comput. Mech. 3 (2007) 271-292

[9] EN 1990 Eurocode - Basis of structural design. CEN 2002.

[10] Smoke Control in road Tunnels, PIARC 05.05.B 1999.

[11] Guarascio M., Lombardi M., Rossi G., Sciarra G., Risk analysis of road and rail tunnels for integral design. 